To cite as: Saidani, M, Pan, E, \& Kim, H. "Switching From Petroleum- to Bio-Based Plastics: Visualization Tools to Screen Sustainable Material Alternatives During the Design Process." Proceedings of the ASME 2020 International Design Engineering Technical Conferences and Computers and Information in Engineering Conference. Volume 6: 25th Design for Manufacturing and the Life Cycle Conference (DFMLC). Virtual, Online. August 17-19, 2020. V006T06A030. ASME. https://doi.org/10.1115/DETC2020-22429

Proceedings of the ASME 2020
International Design Engineering Technical Conferences
and Computers and Information in Engineering Conference
IDETC/CIE2020

August 16-19, 2020, St. Louis, MO, USA

IDETC2020-22429

\title{
SWITCHING FROM PETROLEUM- TO BIO-BASED PLASTICS: VISUALIZATION TOOLS TO SCREEN SUSTAINABLE MATERIAL ALTERNATIVES DURING THE DESIGN PROCESS
}

\author{
Michael Saidani ${ }^{1}$, Erik Pan, Harrison Kim \\ Department of Industrial and Enterprise Systems Engineering, \\ University of Illinois at Urbana-Champaign, Illinois, 61801, USA
}

\begin{abstract}
The recent development in technology has made bio-based plastics an increasingly attractive alternative to petroleumbased plastics to tackle plastic pollution. However, currently, bio-based plastics have not been widely adopted in the design and manufacturing of new products. To advocate the use of biobased plastics, this paper proposes two visualization-based tools to educate designers and engineers about the availabilities and the properties of different bio-based plastics. After analyzing the literature on visual tools for sustainable design and material selection, two new prototype tools for screening bio-plastic alternatives are designed with the advice and support of the engineers of a major U.S. manufacturer of agricultural equipment. Surveys and focus groups with the manufacturer's engineers are conducted to improve the tools, and a first case study is completed to examine their usefulness.
\end{abstract}

Keywords: Bioplastics, material selection, visualization tool, decision support tool, sustainable design, case study.

$\begin{array}{cl}\text { NOMENCLATURE } \\ \text { Bio- } X & \text { Bio-based material X } \\ P A & \text { Polyamide (nylon) } \\ P B S & \text { Polybutylene succinate } \\ P C & \text { Polycarbonate } \\ P E & \text { Polyethylene } \\ P E T & \text { Polyethylene terephthalate } \\ P H A & \text { Polyhydroxyalkanoate } \\ P H B & \text { Polyhydroxybutyrate } \\ P L A & \text { Polylactide } \\ P P & \text { Polypropylene } \\ P S & \text { Polystyrene } \\ P T T & \text { Polytrimethylene terephthalate }\end{array}$
PUR
$P V C$
Polyurethane
TPS
Polyvinyl chloride
Thermoplastic starch

\section{INTRODUCTION}

\subsection{Context and motivations}

New and advanced bio-based materials are being developed to face urging issues such as the unsustainable use of petroleumbased plastic, which can lead to pollution that endangers natural eco-systems. In fact, the current annual production of petroleumbased plastics is approximately 300 million tons worldwide [1]. It is estimated that 34 million tons of plastic waste are generated each year, and around 8 million tons of plastics enter the oceans every year [2]. Furthermore, the degradation of such nonbiodegradable plastics is a time- and energy-consuming process which is responsible for the emissions of a large amount of carbon dioxide (around $2.8 \mathrm{~kg}$ of $\mathrm{CO}_{2}$ eq. is released per $\mathrm{kg}$ of plastic burned) and other toxic compounds.

Biopolymers appear then as a timely alternative to fossilbased plastics to mitigate these environmental risks. A material is defined as a bioplastic if it is either bio-based, biodegradable, or features both properties. Some researchers also provide a classification of polymers based on feedstock renewability and polymer degradability [3]. Traditional polymers are derived from fossil fuels and are nondegradable in nature, whereas sustainable polymers are sourced from the biomass and can readily degrade in the environment. For instance, bio-plastics can be either biobased and biodegradable (e.g., PLA) or bio-based and durable (e.g., Bio-PE). Interestingly, in the automotive sector, Ford has some parts of its seats made from bio-based materials (soy foam) [4].

\footnotetext{
1 Contact author: msaidani@illinois.edu
} 
To cite as: Saidani, M, Pan, E, \& Kim, H. "Switching From Petroleum- to Bio-Based Plastics: Visualization Tools to Screen Sustainable Material Alternatives During the Design Process." Proceedings of the ASME 2020 International Design Engineering Technical Conferences and Computers and Information in Engineering Conference. Volume 6: 25th Design for Manufacturing and the Life Cycle Conference (DFMLC). Virtual, Online. August 17-19, 2020. V006T06A030. ASME. https://doi.org/10.1115/DETC2020-22429

Yet, the actual market share of bioplastics represents less than $2 \%$ of the total plastics market [1]. According to the Nova Institute, the global production capacity of bioplastics reach more than 2 million tons in 2018, bio-PET representing more than $25 \%$ of this total, starch blends $18.2 \%$, bio-PA $11.6 \%$ PLA $10.3 \%$, bio-PE 9.5\%, while other bio-based plastic such as bioPP are currently in development and predicted to be available at a commercial scale in 2023 . While the production capacity of bioplastics is expected to grow in the next few years $[4,5]$, fostering their appropriate consideration and uptake during the design process of new product development is of the utmost importance. One of the key challenges here is informing the industrial companies, notably educating their designers and material engineers, about the promising use of bio-based plastics in their product as potential greener alternatives.

\subsection{Objectives and research approach}

The present study has been conducted in close collaboration with a major manufacturer of agricultural equipment in the U.S. with the purpose to ease the identification and selection of sustainable material alternatives for the products they develop. The sustainability department of the company with whom we collaborated through this study was particularly willing to educate and inform the design and material engineers on the potential of sustainable materials alternatives, with a focus on bio-based plastics. These novel materials are seen as an opportunity to improve the environmental performance of their equipment, while still considering trade-offs with cost, key material properties, and suppliers.

In this context, the questions we set out to answer are, therefore: What are the environmental benefits of potentially suitable bio-based plastic alternatives in comparison to conventional ones? How to facilitate and ensure the selection of greener materials by industrial designers and engineers during the (re)design and development process of products? In this paper, we argue that to further integrate environmental sustainability into conceptual or preliminary design phases, visualization tools (either purely graphical and static, or computer-based and dynamic) can be an effective means to influence sustainable design $[6,7,8]$, e.g., by the fostering the selection and use of novel bio-based materials. The main aim is thus to create and consolidate a knowledge base on the environmental impact and key properties of bio-based plastics alternatives to conventional petroleum-based ones, as well as to figure out how to disseminate effectively such new information to designers and material engineers. This paper proposes as such new visualization tools to heighten awareness on bio-based plastic alternatives, to facilitate the screening of suitable sustainable alternatives in new product development, and ideally, will contribute to their broader adoption in new designs and products.

First, available bio-based plastics have to be identified and analyzed in comparison with conventional plastics in terms of material properties, cost, and environmental impact. In parallel, as illustrated in Fig. 1, after examining the material selection phase during the design process, various ways of visualizing and comparing the characteristics of materials are reviewed. Focus groups and discussions with designers and material engineers are then conducted to get feedback on existing visualization-based tools for material screening. On this basis, two complementary visualization-based tools - that can still be used independently are prototyped to help designers screening suitable bio-based plastics substitutes to petroleum-based ones: (i) one static, graphic tool that can be displayed on a screen or printed on a poster, providing a visual overview of bio-based plastics alternatives and enabling rapid comparison with conventional plastics; (ii) one dynamic, web-based tool containing more information to be displayed to fine-tune the search on appropriate materials. Eventually, a case study on two agricultural equipment is carried out to highlight the potential environmental benefits of switching from petroleum-based plastics to bio-based substitutes.

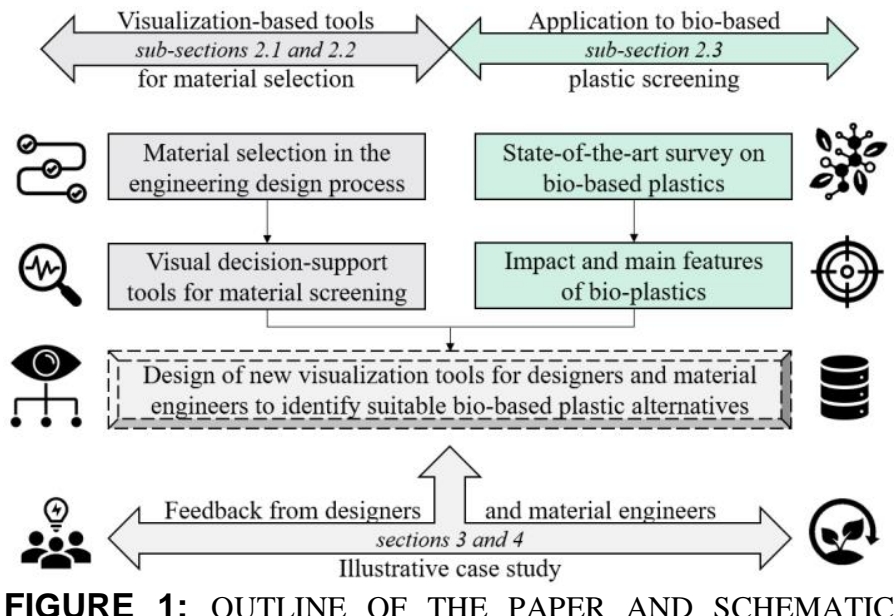
ILLUSTRATION OF THE RESEARCH APPROACH

\section{LITERATURE REVIEW}

\subsection{Material selection in the design process}

Materials selection is one of the main phases of the product design process and can have a significant impact on the overall lifecycle of products [6, 7]. As such, appropriate materials selection is key to sustainable design. According to Ashby [9], the material selection process can be generically mapped as a four-step process: (i) translation of design requirements, (ii) screening using constraints to eliminate non-suitable materials, (iii) ranking alternatives using objective functions, and (iv) seeking supporting information before the final decision.

In all, the selection of sustainable material is a complex multi-criteria decision making (MCDM) problem, where various performance criteria have to be considered by material and design engineers. A large number of factors have indeed to be taking into account when looking for the right material(s), i.e., when designers and/or engineers select a material, they must 
To cite as: Saidani, M, Pan, E, \& Kim, H. "Switching From Petroleum- to Bio-Based Plastics: Visualization Tools to Screen Sustainable Material Alternatives During the Design Process." Proceedings of the ASME 2020 International Design Engineering Technical Conferences and Computers and Information in Engineering Conference. Volume 6: 25th Design for Manufacturing and the Life Cycle Conference (DFMLC). Virtual, Online. August 17-19, 2020. V006T06A030. ASME. https://doi.org/10.1115/DETC2020-22429

consider and fulfill several quantitative requirements among the following list [10]: (i) mechanical properties (e.g., strength), (ii) fabrication requirements (e.g., machining ability), (iii) economic requirements, (iv) maintenance, (v) thermal and radiation properties, (vi) corrosion/oxidation, (vii) wear, (viii) physical properties (e.g., density), (ix) chemical properties, (x) electrical properties, (xi) acoustical properties, (xii) optical properties, (xiii) dimensional properties, (xiv) business issues, (xv) life of component factors, (xvi) availability, (xvii) esthetic attributes, and (xviii) eco-properties (e.g., carbon footprint, recyclability).

MCDM approaches for material selection have been extensively reviewed and classified in the literature. Many mathematical models for MCDM are actually available, such as the technique for order performance by similarity to ideal solution aiming to select the optimal green material for sustainability based on the product's requirements [11]. Yet, as a first step to screen greener material alternatives and to be effectively used by industrialists, such complex approaches and scoring systems might not be the most practical option from the standpoint of industrial designers or material engineers. The present study aims to avoid overcomplicating methods and to smooth the thinking process of design engineers when searching for new suitable and more sustainable materials. In fact, to simplify and facilitate the first screening of potentially sustainable material alternatives, we argue that an integrated visualization tool enabling a straightforward comparison between materials can be a practical solution for designers and materials engineers with no or low prior background on environmental sustainability.

Several tools and resources have been increasingly developed since the 2000 s to support the material selection process, including material databases, evaluation and visualization tools, as reviewed by Lofthouse [12]. In this line, Zarandi et al. [13] came up with a classification of previous researches that developed expert systems for material selection. They proposed a methodology based on a decision tree for environmental feasibility analysis to support the preliminary filtering of materials through the lens of sustainability. Overall, the screening methods available for materials selection range from simple guidelines to sophisticated computer-based platforms, integrated with other design support tools [10]. One of the most acknowledged approaches for green material selection is the life cycle assessment (LCA) methodology. It ensures the environmental sustainability of chosen materials when developing products. Yet, conducting an LCA can be timeconsuming, and require not only a significant amount of data but also a certain expertise on environmental impact assessment and related software, which is a hindrance to its wider adoption by industrialists. Furthermore, current LCA software and tools for analyzing and visualizing environmental results are not sufficiently integrated with enterprise knowledge management systems [8]. On this basis, providing designers and material engineers with visual and straightforward tools to screen new, potentially suitable and sustainable materials during the design process appears as a relevant solution to support the selection of greener materials.

\subsection{Visualization-based tools for materials screening}

Effective data visualization is a crucial enabler to foster sustainable change [14]. Design for persuasion, including visual feedback during the use phase of devices or electronic appliances, can contribute to increasing the ecological awareness of users so that they adjust their behavior to reduce their impact. For instance, an ad hoc eco-visualization of energy or water consumption in real-time can drive a more environmentally conscious action from consumers [15]. Likewise, all along the design and development process, data visualization can be a valuable tool for designers to enhance the processing of information needed to make well-informed decisions, integrating parameters related to environmental sustainability [16]. In comparison with eco-visualization during the usage phase, developing information visualization tools for designers is another challenge because such tools shall support the generation of insights through the interactive exploration of designs and performance indicators [17].

Visual analytics tools can leverage the ability of computerbased tools to gather, process, and summarize data along with the ability of experts (designers, engineers) to foster sustainable product design. By reviewing visualization-based tools for sustainable design, Ramanujan et al. [17] pointed out that while the number of visual analytics tools implemented in the design process is relatively small, further research on visual analytics tools can address the existing challenges in sustainable design. According to the authors, designing visualization-based tools for sustainable product development requires research in: (i) sustainable design process, (ii) data-driven approaches for lifecycle data analysis, and (iii) computer-supported, interactive, visual interfaces. Notably, they recommend that future tools will have to work across multiple data types, visual representations, and stakeholders. Yet, their study of information visualizationbased tools was carried out in the light of exploring and comparing existing designs to compare the impacts of design alternatives, and was therefore not particularly focused on screening sustainable materials or bio-based plastics.

As a useful resource, the European Commission [18] made a comprehensive inventory of visualization-based tools to figure out what are the possibilities of developing new and augmented ones. Cerdas et al. [19] also reviewed and mapped several visualization techniques - bar chart, pie chart, graph chart, spider diagram, box plot, Sankey diagram, tree maps, heat maps - with their capabilities to represent and communicate on: (i) multiple impact categories, (ii) contribution of system elements and life cycle phases, (iii) trade-offs, and (iv) decision implication. They conclude on the need to develop new and improved techniques to visualize LCA results in order to effectively support decisionmaking [19]. The main visual limitations of existing LCA software often reported in the literature include: "cluttered and chaotic workflow" [20], lack of proper visualization on 
To cite as: Saidani, M, Pan, E, \& Kim, H. "Switching From Petroleum- to Bio-Based Plastics: Visualization Tools to Screen Sustainable Material Alternatives During the Design Process." Proceedings of the ASME 2020 International Design Engineering Technical Conferences and Computers and Information in Engineering Conference. Volume 6: 25th Design for Manufacturing and the Life Cycle Conference (DFMLC). Virtual, Online. August 17-19, 2020. V006T06A030. ASME. https://doi.org/10.1115/DETC2020-22429

environmental trade-offs. Note also that visualization requirements might differ according to the target group, e.g., an LCA practitioner would be looking for an in-depth understanding (i.e., multiple impact categories, contribution analysis, uncertainties). In contrast, a non-LCA (designer, marketing department) expert would look for easily interpretable information, allowing time-efficient decision implication with a depiction of trade-offs [19]. In the following paragraphs, we take a deeper look at key and interesting visualization tools - as an inspiration source - to build new and augmented ones designed for materials screening.

Back in the 1990s, Ashby [9] proposed a novel materialsselection procedure making use of "Materials Selection Charts", also known as Ashby diagrams, to display material property data and performances indices on a two-dimensional graph. Ashby diagrams are still taught (and used) today and have been implemented into several software platforms. Yet, such diagrams are commonly deployed in mechanical engineering [21], and a few Ashby-like charts have been developed by considering environmental impacts [22]. They usually display two of the following properties [21]: Young's modulus, density, mass, strength, electrical/thermal properties, or cost. The main advantages of Ashby diagrams are the twofold: (i) they provide a convenient way to compare materials according to two dimensions and assess potential trade-offs; (ii) they already implemented in mechanical engineering education, so engineers are likely to be familiar with this type of visual.

More recently, web-based tools for materials selection, such as the Idemat tool [23], have been developed to facilitate designers and engineers in their choice of materials. The Idemat application contains sustainability-related data in an open-access format for hundreds of materials, including their eco-costs and carbon footprints. The developers of this application [23] claim that it is lightweight, user-friendly, highly visual, and aims to inspire designers with descriptive texts and images. Yet, few biobased plastics are included in the present database. Also, the authors recognized that it needs further testing in a realistic business environment to allow designers to select materials with low environmental impacts effectively.

Other interesting and simple visualization-based tools have been developed as well by researchers in the past few years. For instance, the "Green Arrow" for plastics [24], as shown in the center of Fig. 2, is helpful to provide a quick material suggestion on sustainable materials that share the same "good for" labels. For example, designers could rapidly identify that PLA might be a suitable greener substitute to PP (in terms of material features, both have "eating/drinking", "laser-cutting", and "bearing surface" compatibility). The "Metal-Wheel" [25] is a visualization tool to assist product designers in finding favorable and compatible material connections, so as to ease the end-oflife processing of products.

\subsection{Impact and main features of bio-plastics}

The potential benefits of substituting petroleum-based plastics by suitable bio-plastics alternatives can be summarized as follows [1, 26]: (i) mitigation of carbon footprint. Conventional plastics require fossil fuel as a primary raw material, whereas bio-based plastics are made from biomass, which absorbs carbon dioxide during its growth. Also, petroleum-based plastics require more energy during the development process (such as PP with around $2 \mathrm{~kg}$ of $\mathrm{CO} 2 \mathrm{eq}$. emitted per $\mathrm{kg}$ of plastic produced) when compared with their drop-in bio-plastic counterparts; (ii) possible cheaper alternative in the long run, by reducing reliance on non-renewable petroleum-based feedstocks; (iii) contribution to the local and farming economy, by increasing the value of agricultural byproducts; (iv) diversion of plastic waste from landfill thanks to multiple end-of-life options for bio-plastics (e.g., recycling into new products, input to produce bio-diesel). While in most situations, a general rule of thumb would be recommending the use of bio-based materials instead of fossil fuels when possible, it remains essential to quantitatively be informed on the impacts induced by the production, use and end-of-life phases of such bio-based materials (e.g., potential negative impact transfers or rebound effects caused by a change in land use, or by the use of fertilizers required for efficient biomass production) [27].

Regarding the environmental impacts of bio-based plastics, according to our extensive search, there is currently no satisfactory database sufficiently complete and up-to-date. The Sustainable Biomaterials Collaborative [4] made an inventory of bio-based plastics, including different resins available, examples of companies producing them, and the percent bio-based content of the resin and its biodegradability, but no further information on their environmental footprint. The existing and freely accessible databases of sustainable materials are mostly intended for green buildings [28]. They do not include quantitative information on bio-based plastics, in addition to not being updated on a regular basis. Even commercial material selection software that includes bio-based plastics in their database lack of quantitative information on the environmental footprint of such novel bio-based materials. For instance, the latest CES Selector version developed by Granta Design [29] provides a comprehensive list of features for conventional plastics, including: general information (designation, trade name, typical uses), composition, price, physical properties, mechanical properties, impact and fracture properties, thermal properties, electrical properties, magnetic properties, optical, aesthetic and acoustic properties, healthcare and food, restricted substances risk indicators, absorption and permeability, durability, chemical resistance of polymers, primary production energy, processing energy, carbon and water footprint water, recycling and end of life. Yet, for the bio-based plastics included in their software, the information related to the price and environmental performance were not yet available. The same applies to the typical LCA software and their current databases.

As a consequence, to build a sound visualization tool on biobased plastics alternatives, state-of-the-art studies have been 
To cite as: Saidani, M, Pan, E, \& Kim, H. "Switching From Petroleum- to Bio-Based Plastics: Visualization Tools to Screen Sustainable Material Alternatives During the Design Process." Proceedings of the ASME 2020 International Design Engineering Technical Conferences and Computers and Information in Engineering Conference. Volume 6: 25th Design for Manufacturing and the Life Cycle Conference (DFMLC). Virtual, Online. August 17-19, 2020. V006T06A030. ASME. https://doi.org/10.1115/DETC2020-22429

reviewed and cross-checked to get quantitative data on the carbon emissions attributed to the production and processing phases (cradle-to-gate analysis) of such plastics: Bio-PA [30]; Bio-PBS and Bio-PP [31]; Bio-PE, and Bio-PET [32]; Bio-PTT, TPS, and starch plastic [1]; Bio-PVC [33]; PHA, and PHB [34]; PLA [35]; and recycled plastics [33]. For the other main features of both petroleum- and bio-based plastics, two freely accessible online resources have been used [36, 37], and additional sources have been exploited to have a reasonable estimate of their costs [38]. Additionally, Spierling et al. [1] analyzed the technical substitution potential for bio-based plastics, describing which fossil-based plastics (PE, PP, PVC, PS, PET, and PUR) can be replaced by bio-based ones based on similar properties. Regarding the end-of-life impacts and recyclability of (biobased) plastics, except for PET- and PE-based products for which most recycling centers have the equipment to process these plastics, numerous other plastic-based products cannot actually be easily recycled (e.g., PP can sometimes be recycled, while PVS or PS are rarely recycled plastics). Bio-based drop-in plastics such as Bio-PE or Bio-PET that are chemically identical to their respective petroleum-based versions can be integrated into well-established and streamlined recycling channels. Other bio-based plastics shall be recycled in separate streams, but only if a sufficient volume is reached for each type, for feasibility and profitability reasons. For instance, a severe incompatibility is notably pointed out between PLA and PET recycling [39].

\section{DESIGNING INTEGRATED VISUAL-BASED TOOLS FOR DESIGN AND MATERIAL ENGINEERS}

To first understand the current material selection process of the industrialist supporting this study, discussions have been carried out with a training engineer (who rotated on a semester basis in the design and material departments) about the workflow of how materials are selected for of a given part. The Prospector, including an extensive material database [40], is the tool used to search for potentially suitable material, "to narrow down the search before testing based on required material properties", as indicated by the engineer. This tool is convenient to access material datasheets, to compare typical values, as well as to find alternatives and supplier information. Still, it does not include the environmental performance of materials and the bio-based material options are currently very limited. Thus, an interesting add-on feature would be to recommend similar material in properties but that are more environmentally-friendly. For instance, the first step could be to "find out similar materials in terms of required properties (e.g., mechanical)" and, among the similar materials, the second step would be to "recommend the ones with better sustainable performance (e.g., providing environmental impact savings with an acceptable cost)".

As a follow up to these initial discussions, two focus groups gathering two designers and two material engineers have been conducted to: (i) further understand their material selection process and tools used, (ii) present different visual solutions for sustainable material screening, and (iii) get feedback on what they value most or would like to have displayed on such visualization tools. Different types of visualization tools were shared, from simple educational graphics to further data-centric interfaces, as illustrated through Fig. 2. It has been found that designers and material engineers with no or low background on environmental impact assessment would value first educational graphics, such as the 1-D "Green Arrow", to increase familiarity and awareness on sustainable material alternatives. Then, to make decisions, more quantitative information on material properties would be required, and Ashby-like diagrams or their Prospector tool appear as convenient solutions for material engineers. They also cautioned against overloading the graphics with too much information. Interestingly, it has been noted their current material selection tool, the Prospector is actually used by material engineers but barely adopted by designers.

Eventually, most common visualization-based tools that could be used to inform engineers of the environmental impact of different materials have been put together in a survey, including (see Fig. 2): Ashby diagram, scatter plot, bar chart, radar chart, arrow, table, textual information sheet. The following questions were asked: (i) According to you, is this tool format fits better for decision-support in material selection and awareness on sustainable alternatives? (ii) What information

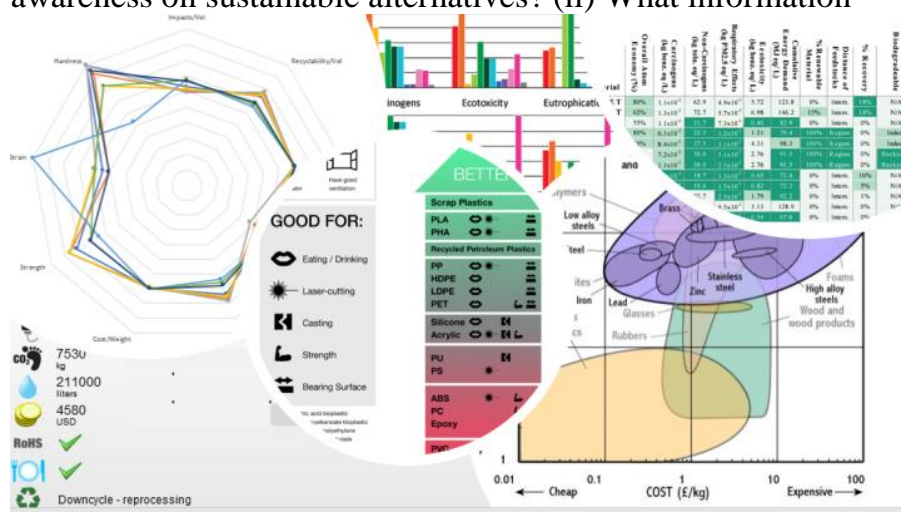

FIGURE 2: OVERVIEW OF EXISTING VISUALIZATION TOOLS FOR MATERIAL SCREENING AND SELECTION

relevant or valuable for material selection? (iii) How would you assess the design and user-friendliness of this tool, and what could be improved (in terms of design or information displayed)? (iv) Which combination of the tools presented before would you find useful? (v) Would you find added value to a web-based app of such visual tools, e.g., to select which information to display by just clicking on well-designed boxes?

When asked to rank the tools or visual formats that fit the best for screening material alternatives, no clear common trend was found in the results of what practitioners value most in this context, even if the Ashby diagram, the arrow, and the bar chart usually had a better ranking than the other options. An interesting idea appears then to merge the valued features (e.g., contrasted colors, logos, multi-dimensional visualization on a single view) of preferred tools to design augmented, practical, and more integrated visualization tools. For instance, one mentioned that 
To cite as: Saidani, M, Pan, E, \& Kim, H. "Switching From Petroleum- to Bio-Based Plastics: Visualization Tools to Screen Sustainable Material Alternatives During the Design Process." Proceedings of the ASME 2020 International Design Engineering Technical Conferences and Computers and Information in Engineering Conference. Volume 6: 25th Design for Manufacturing and the Life Cycle Conference (DFMLC). Virtual, Online. August 17-19, 2020. V006T06A030. ASME. https://doi.org/10.1115/DETC2020-22429

combining the quantitative bar chart and the contrasted arrow and logos "might be nice", and then to "have an app or site that would allow you to drill further into these materials and list some applications".

\section{RESULTING PROTOTYPE TOOLS AND FIRST APPLICATION}

\subsection{Newly developed visualization-based tools}

With this background, two visualization-based tools have been prototyped. The first prototype tool, available through Fig. 3 , is a hybridization of the contrasted arrow with logos [24] and a bar chart with quantitative data on the cradle-to-gate carbon footprint of plastics. In Figure 3, all the GWP values are cradleto-gate, i.e., including the processing and manufacturing impact of $1 \mathrm{~kg}$ of plastic ready to be used. Additional key material information has also been embedded, such as density, price, recyclability, market availability and other mechanical characteristics. It allows a first screening to identify potential sustainable bio-based plastic alternatives. It can either be displayed on a screen, or printed, e.g., to be placed on an engineer's desktop. A more complete (i.e., including further materials) and interactive version of this tool (e.g., enabling to only display the materials that meet the desired features) is under development and expected to be presented at the Design Tool Showcase of this conference. An Excel-based macro has been created to generate the bar chart, as well as to easily add other materials and update the environmental impact values when necessary. Note that a colorblind-friendly version (blue and orange palette) is available on-demand, and more visual designs of this tool (including a version with more materials, as well as an interactive version) are expected to be presented at the Design Tool Showcase of this conference [41]. The second tool is a web application, based on the principle of Ashby diagrams, that contains further materials information. It gives the user more options to navigate and customize in real-time the visuals. It can be accessed and experimented online through the following link: https://ericpzh.github.io/smaterialsadvisor/. This visualization tool is a web-based app built using the React JS framework. The front-end-only app is built based on the data provided by the Idemat database [23]. The user interface has been designed using components from Semantic UI, and the interactive plot is implemented using Plotly.

\subsection{Dissemination to designers, material engineers, and case study}

To keep improving and fine-tuning these tools, we received so far the feedback from one senior material engineer and one designer whose positions involve at some point to define or select an appropriate material for a given part. They notably stated that the first visualization tool (see Fig. 3) "would be userfriendly" and a "good starting point" providing "a lot of information to make initial decisions". As such, it can be specifically useful and valuable for designers who are not usually using the internal Prospector tool of the company for screening suitable and more sustainable materials.

To illustrate how the new visualization tool can be simply used to find out possible bio-based material substitutes to reduce the environmental footprint of products, a case study is performed on two real-world products that are currently containing a non-negligible variety and quantity of conventional petroleum-based plastics. The first product is an autonomous lawn mower weighing approximately $35 \mathrm{~kg}$, including more than $12 \mathrm{~kg}$ of various plastics, as detailed in Table 1. The second product is a heavier tractor-mounted sprayer containing $755 \mathrm{~kg}$ of plastics. Exact weight values have been slightly modified for confidentiality reasons. In this illustrative example, it has been assumed that $1 \mathrm{~kg}$ of conventional plastic $X$ could be replaced by $1 \mathrm{~kg}$ of drop-in bio-based plastic X. For product one, results show that replacing all petroleum-based plastics by suitable green plastic alternatives - according to the proposed visualization tool (see Fig. 3) - could reduce the overall manufacturing impact of this product by $10 \%$ in terms of carbon dioxide emissions. For product two, using new bio-based plastics instead of petroleum-based ones could avoid the emissions of more than half a ton of carbon dioxide by product. 
To cite as: Saidani, M, Pan, E, \& Kim, H. "Switching From Petroleum- to Bio-Based Plastics: Visualization Tools to Screen Sustainable Material Alternatives During the Design Process." Proceedings of the ASME 2020 International Design Engineering Technical Conferences and Computers and Information in Engineering Conference. Volume 6: 25th Design for Manufacturing and the Life Cycle Conference (DFMLC). Virtual, Online. August 17-19, 2020. V006T06A030. ASME. https://doi.org/10.1115/DETC2020-22429

\section{Visualization tool for screening bio-based plastic alternatives}

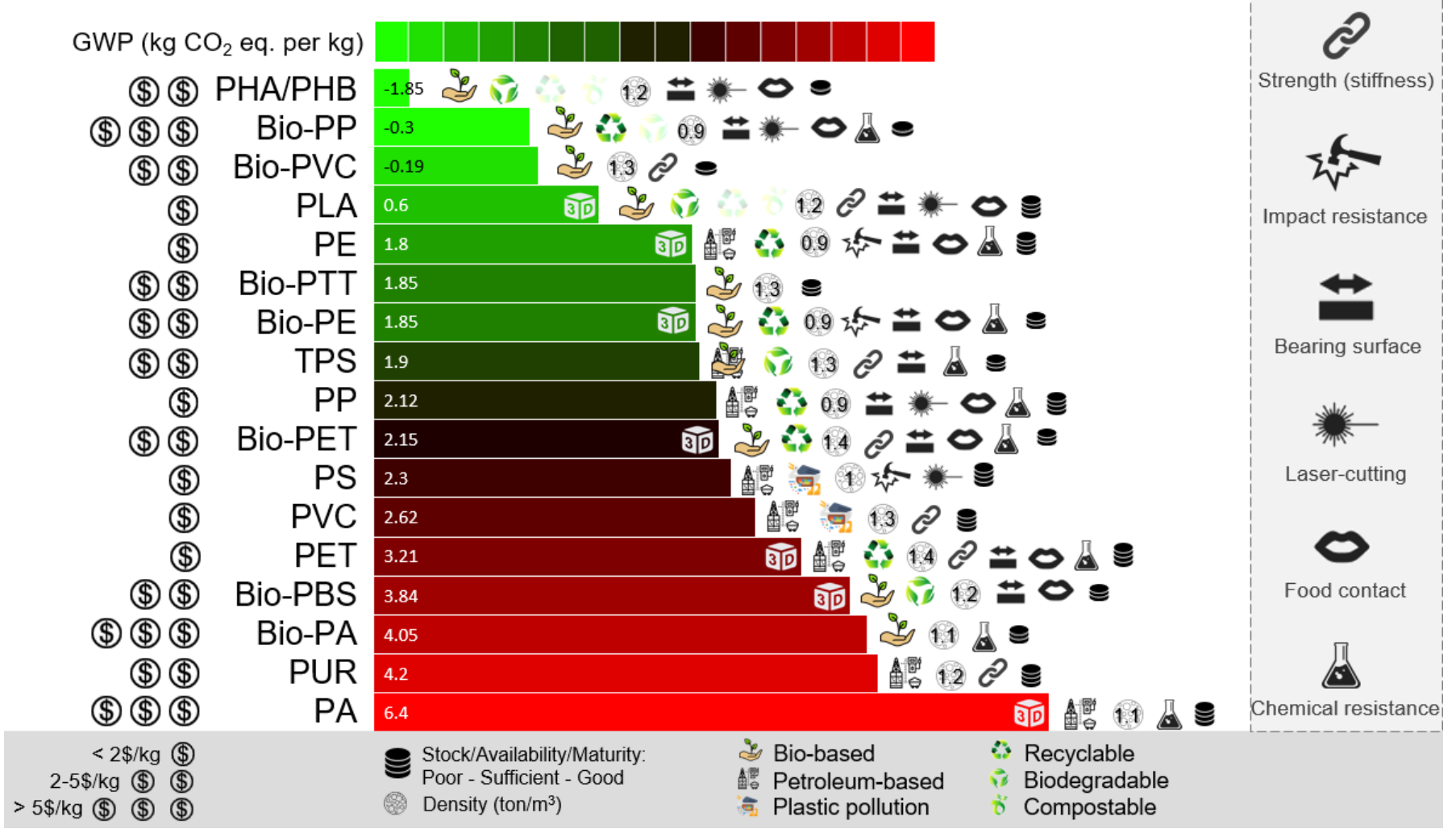

FIGURE 3: NEW VISUALIZATION-BASED PROTOTYPE TOOL TO SCREEN THE PERFORMANCE OF BIO-PLASTIC ALTERNATIVES

\begin{tabular}{|c|c|c|c|c|c|}
\hline \multirow{2}{*}{$\begin{array}{l}\text { Original } \\
\text { plastic } \\
\text { materials } \\
\text { content } \\
\text { (petroleum- } \\
\text { based) }\end{array}$} & \multicolumn{2}{|l|}{ Mass (kg) } & \multirow{2}{*}{$\begin{array}{l}\text { Sustainable } \\
\text { alternatives } \\
\text { (bio-based } \\
\text { or recycled } \\
\text { plastics) }\end{array}$} & \multicolumn{2}{|c|}{$\begin{array}{l}\text { Estimated GWP impact savings } \\
\text { (kg CO}{ }_{2} \text { eq.) }\end{array}$} \\
\hline & $\begin{array}{l}\text { Product } 1 \\
\text { Autonomous } \\
\text { Mower }\end{array}$ & $\begin{array}{l}\text { Product } 2 \\
\text { Tractor } \\
\text { Sprayer }\end{array}$ & & $\begin{array}{l}\text { Product } 1 \\
\text { Autonomous } \\
\text { Mower }\end{array}$ & $\begin{array}{l}\text { Product } 2 \\
\text { Tractor } \\
\text { Sprayer }\end{array}$ \\
\hline $\mathrm{PE}$ & 5 & 480 & Bio-PE & -0.25 & -24 \\
\hline PP & 5 & 60 & Bio-PP & 12.1 & 145.2 \\
\hline PVC & 0.1 & 10 & Bio-PVC & 0.28 & 28.1 \\
\hline PA & 0.1 & 200 & Bio-PA & 0.23 & 470 \\
\hline PUR & 2 & 5 & $\begin{array}{l}\text { Recycled } \\
\text { PUR }\end{array}$ & 4 & 10 \\
\hline Total & 12.2 & 755 & Significance & $\begin{array}{l}\text { Manufacturing } \\
\text { impact reduced } \\
\text { by } 10 \%\end{array}$ & $\begin{array}{l}\text { More than half } \\
\text { a metric ton of } \\
\mathrm{CO}_{2} \text { avoided }\end{array}$ \\
\hline
\end{tabular}

TABLE 1: RESULTS OF THE ILLUSTRATIVE CASE STUDY

\section{CONCLUSION AND PERSPECTIVES}

Novel sustainable materials are being developed to address the pressing issue of plastic pollution, e.g., bio-based substitutes to unsustainable plastics like petroleum-based PVC, which is hard to recycle. While the global production of bio-based plastics (from sustainable feedstocks such as plant fibers, wood, or starches) is expected to increase in the next few years [42], their actual consideration and adoption by designers and material engineers when developing new products can be fostered through the use of practical visualization tool, first to increase the awareness on such alternatives, and then to select a suitable greener option. The use of clear, user-friendly, and accepted visualization-based tools could indeed help design engineers screen suitable sustainable alternatives during the design and development process of products. To ensure informed and sustainable decisions during the material selection process, it is essential that such tools include sound information related to the main features of the materials to be compared, as well as quantitative or relative data related to their economic and environmental performance. Thomas E. Graedel, pioneer researcher in industrial ecology, recently argued for better visualization tools for materials-based decision making, especially to ease the interpretation of numerous and complex data in sustainability science. His research team is experimenting with different visual concepts on a very substantial materials database $[43,44]$, intending to facilitate a deeper understanding of sustainable materials use and management. Concretely, clear and integrated visualization frameworks are essential to advance the implementation and use of sustainability analyses during the design and development of products. They can contribute to bridging the gap between researchers - developing sustainability assessment tools - and industrial practitioners - often nonexperts in environmental assessment, and responsible for making decisions across the product life cycle [45].

To bridge the current knowledge gap on bio-plastics and catalyze their use in new or redesign products, this research 
To cite as: Saidani, M, Pan, E, \& Kim, H. "Switching From Petroleum- to Bio-Based Plastics: Visualization Tools to Screen Sustainable Material Alternatives During the Design Process." Proceedings of the ASME 2020 International Design Engineering Technical Conferences and Computers and Information in Engineering Conference. Volume 6: 25th Design for Manufacturing and the Life Cycle Conference (DFMLC). Virtual, Online. August 17-19, 2020. V006T06A030. ASME. https://doi.org/10.1115/DETC2020-22429

provides an integrated summary - embodied through the design of new visualization tools (see Fig.3) - of the key characteristics and environmental impact footprint (in terms of carbon dioxide emissions) of bio-based plastics as promising substitutes for conventional fossil fuel-based plastics. The newly visualization tools prototyped in this paper differ from the existing tools for material selection by gathering and hybridizing on a single view the valued features (e.g., multi-dimensional data, quantitative bar chart, logos, contrasting colors) of separate tools. As they have already been experienced by a designer and a senior material engineer, another interesting perspective to them would be to create a dynamic dashboard, with a light or customizable user interface, containing two or more visualization-based tools to provide further information and even prompt an action or decision. Also, further experimentations and workshops on these newly developed tools, would be relevant to know better how they can be deployed during the design process, and integrated with other eco-design or eco-innovation tools, to foster the development of sustainable products in industrial practices [46].

Last but not least, while a cradle-to-gate system boundary has been used to compare, quantitatively, and on the same basis, the global warming potential of conventional plastics with their bio-based counterparts, closing-the-loop on plastic is also fundamental to make the plastic industry more sustainable. In the new visualization tool available in Fig. 3, key information is provided regarding the possible end-of-life pathways of both petroleum- and bio-based plastics (i.e., recyclable, biodegradable, compostable). As circular plastics and plastics upcycling are promising challenges [47], further research should be conducted to assess the impact of potential reusable options and end-of-life recovery processes, in order to ensure both environmental and economic profitability [48] when closing-theloop on plastics. In this line, appropriate sustainability and circularity indicators might be helpful to identify and monitor environmentally favorable pathways for bio-plastic waste streams $[49,50]$.

\section{ACKNOWLEDGMENTS}

The authors would like to thank all the designers, materials engineers, and sustainability managers who took the time to provide valuable feedback on the different visualization-based tools for material selection. This material is based upon the work at the University of Illinois partially supported by Deere and Company. Any opinions, findings, and conclusions or recommendations expressed in this paper are those of the authors and do not necessarily reflect the views of Deere and Company.

\section{REFERENCES}

[1] Spierling, S., et al. (2018a). "Bio-based plastics - A review of environmental, social and economic impact assessments". Journal of Cleaner Production, 185, pp. 476-491.

[2] Thakur, S. et al. (2018). "Sustainability of bioplastics: Opportunities and challenges". Current Opinion in Green and Sustainable Chemistry, 13, pp. 68-75.
[3] Zinoviadou, K.G., Gougouli, M., and Biliaderis, C.G. (2016). "Innovative Biobased Materials for Packaging Sustainability". Academic Press, Innovation Strategies in the Food Industry, pp. 167-189.

[4] Sustainable Biomaterials Collaborative. (2019). "Emerging Materials and Products". https://sustainablebiomaterials.org/emerging-materials-andproducts/

[5] Spierling S., et al. (2019). "Bioplastics and Circular Economy - Performance Indicators to Identify Optimal Pathways". Progress in Life Cycle Assessment, Sustainable Production, Life Cycle Engineering and Management, Springer.

[6] McAloone, T. C., and Bey, N. (2009). "Environmental improvement through product development: A guide". Report, Danish Environmental Protection Agency, Copenhagen.

[7] Ramani, K., Ramanujan, D., Bernstein, W. Z., et al. (2010). "Integrated Sustainable Life Cycle Design: A Review". Journal of Mechanical Design, 132(8), pp. 1-15.

[8] Ramanujan, D., Bernstein, W. Z., and Ramani, K. (2017). "Design Patterns for Visualization-Based Tools in Sustainable Product Design". Proceedings of the ASME IDETC/CIE 2017, Cleveland, Ohio, USA, August 6-9, 2017.

[9] Ashby, M. (1992). "Materials selection in mechanical design". Pergamon Press, Oxford.

[10] Jahan, A., Edwards, K. L., and Bahraminasab, M. (2016). "Multi-criteria Decision Analysis for Supporting the Selection of Engineering Materials in Product Design". Butterworth-Heinemann.

[11] Zhang, H., Peng, Y., Tian, G., Wang, D., and Xie, P. (2017). "Green material selection for sustainability: A hybrid MCDM approach”. PLOS One, 12(5), 177578.

[12] Lofthouse, V. A. (2006). "Ecodesign tools for designers: defining the requirements". Journal of Cleaner Production, 14, pp. 1386-1395.

[13] Zarandi, M. H. F., et al. (2011). "A material selection methodology and expert system for sustainable product design". Int J Adv Manuf Technol, 57, pp. 885-9033.

[14] Bjork, C. (2019). https://metabolic.nl/news/why-datavisualization-is-critical-to-driving-sustainable-change/

[15] Kim T., Hong H., and Magerko B. (2010). "Designing for Persuasion: Toward Ambient Eco-Visualization for Awareness". Persuasive Technology, Lecture Notes in Computer Science, 6137, Springer, Berlin.

[16] Stabellini, B., Remondino, C. L., and Tamborrini, P. (2017). "How graphical representation can inspect and communicate sustainability through Systemic Design". The Design Journal, 20(1), pp. 1673-1681.

[17] Ramanujan, D., Bernstein, W. Z., Chandrasegaran, S. K., and Ramani, K. (2017). "Visual Analytics Tools for Sustainable Lifecycle Design: Current Status, Challenges, and Future Opportunities". Journal of Mechanical Design, 139(11), 111415 
To cite as: Saidani, M, Pan, E, \& Kim, H. "Switching From Petroleum- to Bio-Based Plastics: Visualization Tools to Screen Sustainable Material Alternatives During the Design Process." Proceedings of the ASME 2020 International Design Engineering Technical Conferences and Computers and Information in Engineering Conference. Volume 6: 25th Design for Manufacturing and the Life Cycle Conference (DFMLC). Virtual, Online. August 17-19, 2020. V006T06A030. ASME. https://doi.org/10.1115/DETC2020-22429

[18] European Commission. (2016). "Reusable data visualization tools to support data-driven policymaking in the EU". Report, Publications Office of the European Union.

[19] Cerdas, F., Kaluza, A., Erkisi-Arici, S., Böhme, S., and Herrmann, C. (2017). "Improved Visualization in LCA Through the Application of Cluster Heat Maps". Procedia CIRP, 61, pp. 732-737.

[20] Chen, J. (2017). "User Interface \& Data Visualization for Environmental Assessment". Final Capstone Report, Electrical Engineering and Computer Sciences, UC Berkeley.

[21] Holloway, L. (1998). "Materials selection for optimal environmental impact in mechanical design". Materials \& Design, 19(4), pp. 133-143.

[22] University of Cambridge. (2002). "Material Selection Charts".

materials.eng.cam.ac.uk/mpsite/interactive_charts/ http://www-

[23] Meursing, M., Vogtländer, J. G., and Zijlstra, J. J. M. (2015). "Sustainability Inspired Materials Selection App for Designers". Report, Industrial Design Engineering, TU Delft.

[24] Faludi, J. (2015). "Choosing Greener Plastics". https://venturewell.org/wp-content/uploads/Chooser-ChartGreener-Plastics.pdf

[25] Reuter, M. A., et al. (2013) "Metal Recycling: Opportunities, Limits, Infrastructure". Report, UNEP Working Group on the Global Metal Flows to the International Resource Panel, 320p.

[26] Reddy, R. L., Reddy, V. S., and Gupta, G. A. (2013). "Study of Bio-plastics As Green \& Sustainable Alternative to Plastics". International Journal of Emerging Technology and Advanced Engineering, 3(5), pp. 82-89.

[27] Bos, H. L., Meesters, K. P. H., Conijn, S. G., Corré, W.J., and Patel, M.K. (2012). "Accounting for the constrained availability of land: a comparison of bio-based ethanol, polyethylene and PLA with respect to non-renewable energy use and land use". BioFBR, 6(2), pp. 146-158.

[28] Dehn, J. (2014). "Conception and Realization of a Sustainable Materials Library". Materials Experience, Butterworth-Heinemann, pp. 155-168.

[29] Granta Design

(2019).

https://grantadesign.com/industry/products/data/

[30] Evonik. (2019). "Life Cycle Assessment of biobased polyamides Vestamid Terra". Factsheet.

[31] Chen, G. Q., and Patel, M. K. (2012). "Plastics derived from biological sources: present and future: a technical and environmental review". Chemical reviews, 112(4), pp 20822099.

[32] Tsiropoulos, I., Faaij, A. P., Lundquist, L., Schenker, U., Briois, J. F., and Patel, M. K. (2015). "Life cycle impact assessment of bio-based plastics from sugarcane ethanol". Journal of Cleaner Production, 90, pp. 114-127.

[33] Alvarenga, R. A., Dewulf, J., et al. (2013). "Life cycle assessment of bioethanol-based PVC". Biofuels, Bioprod. Bioref., 7, pp. 386-395.
[34] Kendall, A., (2012). "A life cycle assessment of biopolymer production from material recovery facility residuals". Resources, Conservation and Recycling, 61, pp. 6974.

[35] Vink, E. T. and Davies, S. (2015). "Life cycle inventory and impact assessment data for 2014 Ingeo $^{\mathrm{TM}}$ polylactide production". Industrial Biotechnology, 11(3), pp. 167-180.

[36] Material Property Data. (2020). http://www.matweb.com/search/PropertySearch.aspx.

[37] Curbell Plastics.

(2020). https://www.curbellplastics.com/Research-Solutions/Materials

[38] Plasticker.

(2020). https://plasticker.de/preise/pms_en.php

[39] Alaerts, L., Augustinus, M., and Van Acker, K. (2018). "Impact of Bio-Based Plastics on Current Recycling of Plastics". Sustainability, 10, 1487.

[40] Prospector. (2020). https://plastics.ulprospector.com/

[41] Saidani, M., Pan, E., Ng, K., and Kim, H. M. (2020). "New Visualization Tools for Designers to Identify Bio-Based Plastic Substitutes Considering Carbon Footprint and Key Material Properties". ASME IDETC/CIE 2020, St. Louis, MO, USA.

[42] Green Dot Plastics. (2018). https://www.greendotbioplastics.com/future-of-sustainableplastics/

[43] Myers, R. J., Reck, B. K. and Graedel, T. E. (2019). "YSTAFDB, a unified database of material stocks and flows for sustainability science". Sci Data, 6, 84.

[44] Ohno, H., Nuss, P., Chen, W. Q., and Graedel, T. E. (2016). "Deriving the metal and alloy networks of modern technology". Environmental science \& technology, 50(7), 40824090.

[45] Raoufi, K., Taylor, C., Laurin, L., and Haapala, K. R. (2019). "Visual Communication Methods and Tools for Sustainability Performance Assessment: Linking Academic and Industry Perspectives". Procedia CIRP, 80, 215-220.

[46] Saidani, M., Cluzel, F., Leroy, Y., and Auclaire, A. (2016). "Time-efficient eco-innovation workshop process in complex system industries". Proceedings of the International Design Conference, Dubrovnik, Croatia, May 16-19, 2016.

[47] Christensen, P. R., Scheuermann, A. M., Loeffler, K. E., and Helms, B. A. (2019). "Closed-loop recycling of plastics enabled by dynamic covalent diketoenamine bonds". Nature Chemistry, 11, pp. 442-448.

[48] Saidani, M., Kim, H., Yannou, B., Leroy, Y., and Cluzel, F. (2019). "Framing Product Circularity Performance for Optimized Green Profit". Proceedings of the ASME IDETC/CIE 2019, Anaheim, California, USA, August 18-21, 2019.

[49] Spierling, S., et al. (2018b). "Bio-based Plastics - A Building Block for the Circular Economy?" Procedia CIRP, 69, pp. 573-578.

[50] Saidani, M., Yannou, B., Leroy, Y., Cluzel, F., and Kendall, A. (2019). "A taxonomy of circular economy indicators". Journal of Cleaner Production, 207, pp. 542-559. 